\title{
Alelos HLA DQ alfa maternos, pérdida recurrente del embarazo y síndrome de anticuerpos antifosfolípidos
}

\author{
A. E. Beer ${ }^{1}$; J. Y. Kwak ${ }^{2}$; J. Cubillos ${ }^{3}$; P. Sandoval'; J. C. Mendoza ${ }^{5}$ F. Espinel
}

\begin{abstract}
SUMMARY: Autoantibodies to phospholipids antigens APL are associated with a history of RSA in women without autoinmunedisease. APL interfere with the production of prostaciclin allowing the increase of thrombotic events. Phospholipids are compounds of the placental membrane structure and also they have been considered as an adhesion molecules participating in the formation of syncytotrophoblast. Trophoblastic antigens can induce the production of antiphospholipids antibodies. This antibodies can delay the trophoblast development by the action in the adhesion molecules.
\end{abstract}

We have studied 270 women with RSA and 31 women as a control group which had normal pregnancies. The testing included antiphospholipid antibodies and genetic evaluation of class II DQ antigens of the couple.

We have showed APL titles no gretaer than $1 / 25$ in normal pregnant women. In RSA the incidence increases in a fifteen percent with each subsequent pregnancy loss.

We observed an strong correlation between maternal HLA DQ alfa 4.1 (0501) and increase in APL titles in patients who loss their pregnancy again.

KEY WORDS: Antiphospholipids antibodies, RSA recurrent spontaneous abortion, HLA DQ alfa 4.1.

\section{Introducción}

Anticuerpos antifosfolípidos (AAP) son documentados en muchos casos de aborto recurrente espontáneo (ARE) de causa inexplicada. Los anticuerpos antifosfolípidos interfieren con la producción de prostaciclina causando un incremento en la agregación plaquetaria, vasoconstricción, trombosis e infartos placentarios (5-6). Los fosfolípidos son componentes integrales de las membranas de las vellosidades placentarias y actualmente se conoce que sirven como moléculas de adhesión en la formación del mioblasto a mioepitelio, fibroblasto a fibroblasto sincitial y tal vez en la formación del citotrofoblasto a sincitiotrofoblasto (7). La estimulación antigénica del trofoblasto durante el embarazo podría inducir la producción de anticuerpos antifosfolípidos. Estos anticuerpos podrían retardar el desarrollo subsecuente del trofoblasto a través de su acción en los fosfolípidos de adhesión necesarios para el desarrollo del citotrofoblasto al sincitiotrofoblasto $(4,8)$.

Resultados de estudios sobre la presencia de anticuerpos antifosfolípidos en mujeres difieren ampliamente. Muchos

Profesor en Microbiología e Inmunología. Profesor en Obstetricia y Ginecología, Universidad de Ciencias de la Salud. Escuela Médica de Chicago.

Universidad de Ciencias de la Salud. Escuela Médica de Chicago. Coordinadora Laboratorio. Unidad Inmunología y Genética HIULVS.

Residente III Año Ginecología y Obstetricia HIULVS.

Instructor Asistente. Colegio Mayor del Rosario.

Coordinador. Unidad Inmunobiología y Genética HIULVS. estudios carecen de controles adecuados y en la mayoría el único fosfolípido estudiado es la cardiolipina. Sinembargo se ha reportado una fuerte correlación entre anticuerpos antifosfolípidos e historia de pérdida recurrente del embarazo (1-4).

El presente estudio fue diseñado para evaluar la incidencia y el título de anticuerpos antifosfolípidos durante el embarazo en 270 mujeres con ARE y en 31 mujeres sin historia de ARE quienes experimentaron un embarazo y parto normal. Las pacientes que tuvieron recién nacidos vivos y las que presentaron nuevamente aborto espontáneo a pesar de tratamiento aloinmune y autoinmune adecuado, fueron evaluadas para tipifación de HLA DQ alfa por técnica de genética molecular para determinar si el alelo HLA específico está relacionado a la producción de autoanticuerpos.

\section{Materiales y métodos}

Treinta y un mujeres sin historia de ARE fueron estudiadas para autoanticuerpos a antígenos fosfolipídicos cada trimestre durante el embarazo y al momento del parto por métodos previamente reportados (4). La sangre de cordón fue también evaluada para AAP. Todas las muestras fueron tituladas para AAP. Doscientos setenta mujeres con 3 o más ARE se le practicaron las pruebas para aloinmunidad y autoinmunidad. Mujeres con fallas en el reconocimiento Aloinmune fueron inmunizadas con linfocitos y todas desarrollaron niveles adecuados de anticuerpos antipaternos 
antes de su nuevo embarazo. Pacientes con anormalidades serológicas autoinmunes fueron tratadas preconcepcionalmente con ASA Heparina y Prednisona cuando era indicado, según reportes previos (9).

Evaluación molecular genética HLA de antígenos de clase II DQ de parejas, fueron realizados utilizando aislamiento del DNA, amplificación y pruebas de oligonucleótidos apropiadas (10).

Títulos de autoanticuerpos a antígenos nucleares y de fosfolípidos fueron realizados cada 2 semanas durante el embarazo, en el momento del parto, o en el momento de la pérdida (11).

\section{Resultados}

\section{Títulos de AAP en mujeres con embarazos normales}

Las figuras 1 y 2 muestran los títulos de AAP a los 6 epítopes en mujeres con embarazos normales, estudiados secuencialmente durante la gestación y en sangre de cordón al momento del parto.

La figura 3 muestra los niveles de AAP en mujeres control normal de acuerdo con su número de gestaciones. No hay incremento en los títulos de AAP en este grupo con el incremento de la gravidez ni de la paridad. En mujeres con ARE de etiología Aloinmune, la incidencia de AAP se incrementa en un $15 \%$ con cada una de sus pérdidas (9).

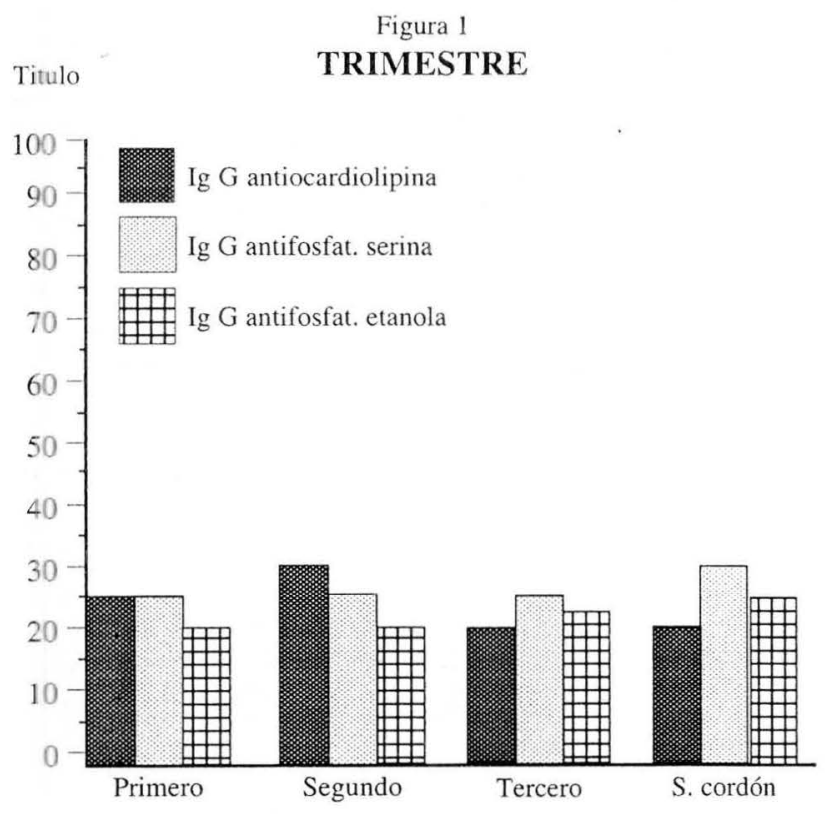

\section{Títulos de AAP en mujeres con ARE}

La figura 4 describe los títulos de AAP a la cardiolipina en mujeres que eran positivas para AAP cuando empezaban su embarazo. Una reducción en los títulos de los anticuerpos ocurren en mujeres que llevan a término su embarazo, y elevaciones significativas se encuentran en aquellas que nuevamente pierden su gestación. Con respecto a los AAP estudiados (anticuerpos a fosfatidilserina, fosfatidilinositol, fosfatidilglicerol, cardiolipina, fosfatidiletanolamina y áci-
Figura No. 2

\section{TRIMESTRE}

Titulo

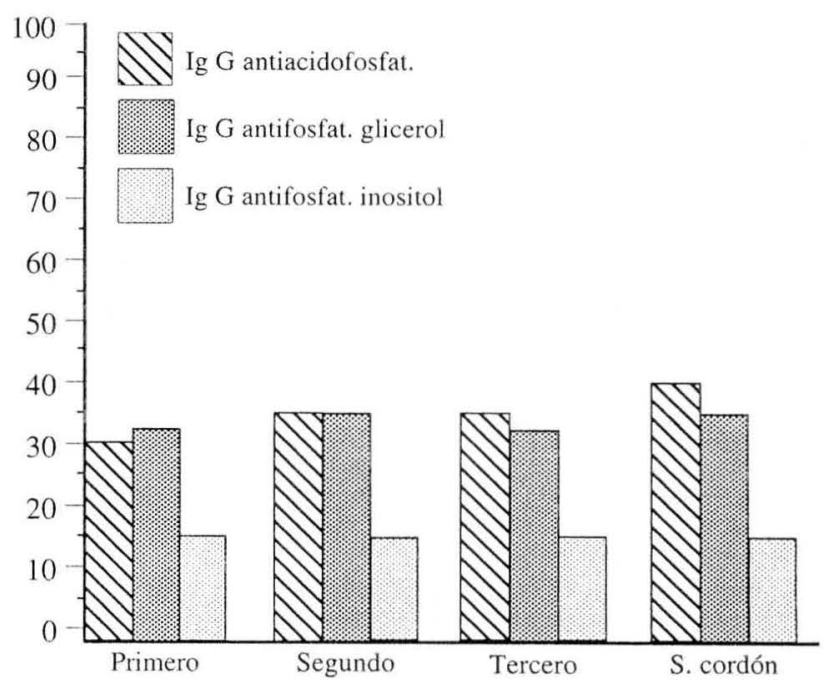

do fosfatídico) elevaciones en sus títulos predicen una pérdida del embarazo subsecuente que ocurría hacia las 10 semanas en todas las pacientes estudiadas. Este incremento en el título y un mal pronóstico en el embarazo ocurrieron a pesar de un óptimo tratamiento Alo y Autoinmune. La dinámica de este proceso fue la evocación de la respuesta de anticuerpos Rh en mujeres con enfermedad Rh, lo que sugiere que el feto es quien inicia la respuesta en su madre portando antígenos carentes en aquellas que no muestran elevación en los títulos de AAP.
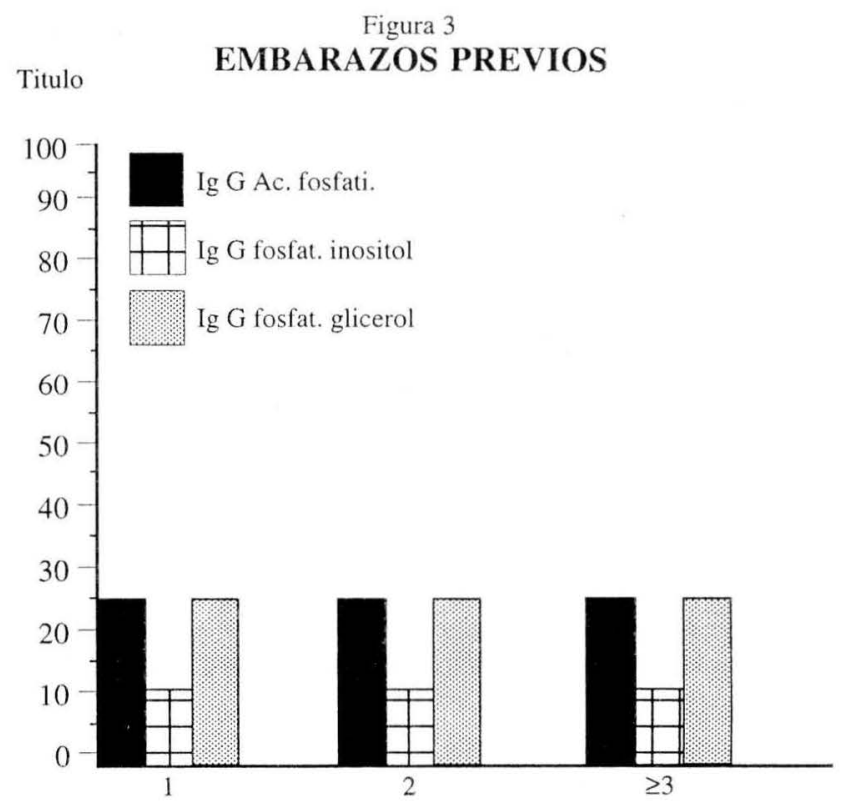

\section{Análisis de HLA DQ alfa}

Todas las parejas que experimentaban una pérdida repetida aún con tratamiento Alo o Autoinmune, fueron analizadas para alelos DQ ALFA. La figura 5 documenta una fuerte asociación con el HLA DQ ALFA 4.1 (0501) materno en 


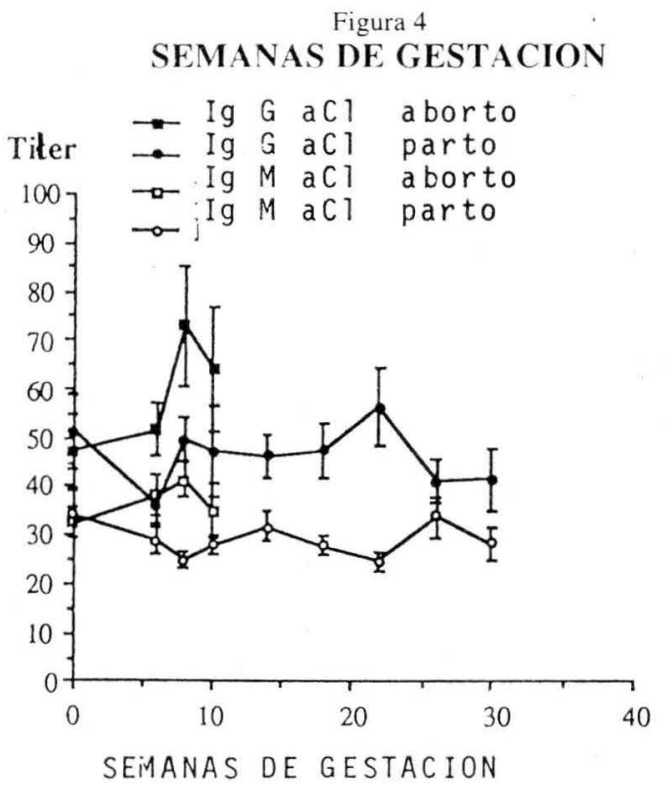

mujeres que experimentaban una nueva pérdida del embarazo. Madres que fueron DQ ALFA 4.1 (0501) negativas no desarrollaron AAP. Madres que fueron DQ ALFA 4.1 (0501) negativas no desarrollaron AAP después de su pérdida del embarazo. Muchos de los fetos de madres HLA DQ ALFA 4.1 (0501) positivas fueron HLA DQ ALFA 4.1 (0501) homocigotos. No se identificaron recién nacidos vivos homocigotos para el HLA DQ ALFA 4.1; sin embargo, la mayoría del primer recién nacido de parejas abortadoras secundarias fueron HLA DQ ALFA 4.1 (0501) homocigoto (BEER Y COLS. trabajo en proceso). Estudios posteriores para determinar si ciertos alelos HLA del primer niño de parejas abortadoras secundarias inician el síndrome AAP que perjudica embarazos subsecuentes similar al síndrome de isoinminización $\mathrm{Rh}$ que conocemos.

La figura 6, muestra la especificidad del epítope de AAP y el porcentaje positivo en mujeres HLA DQ ALFA 4.1 (0501) positivas y HLA DQ ALFA 4.1 (0501) negativas.

\section{INCIDENCIA DE AUTOANTICUERPOS}

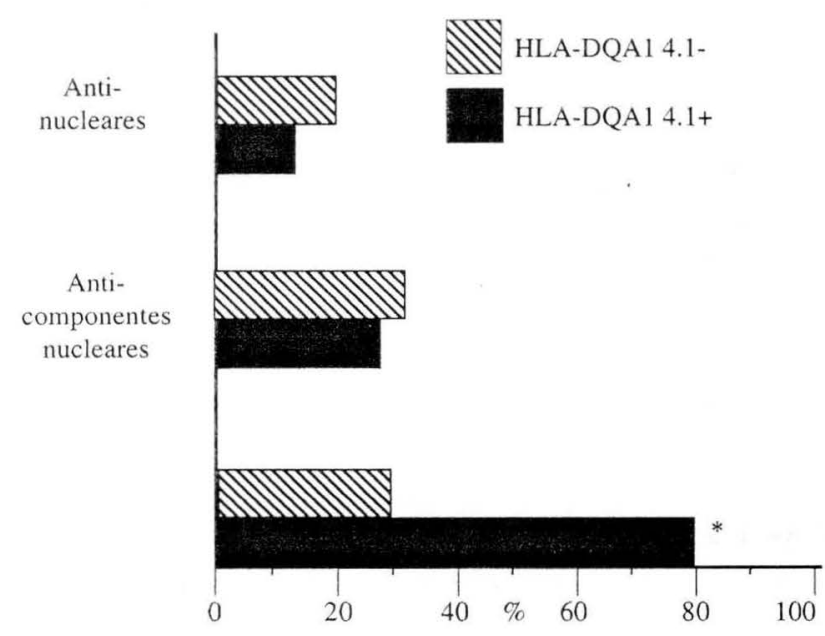

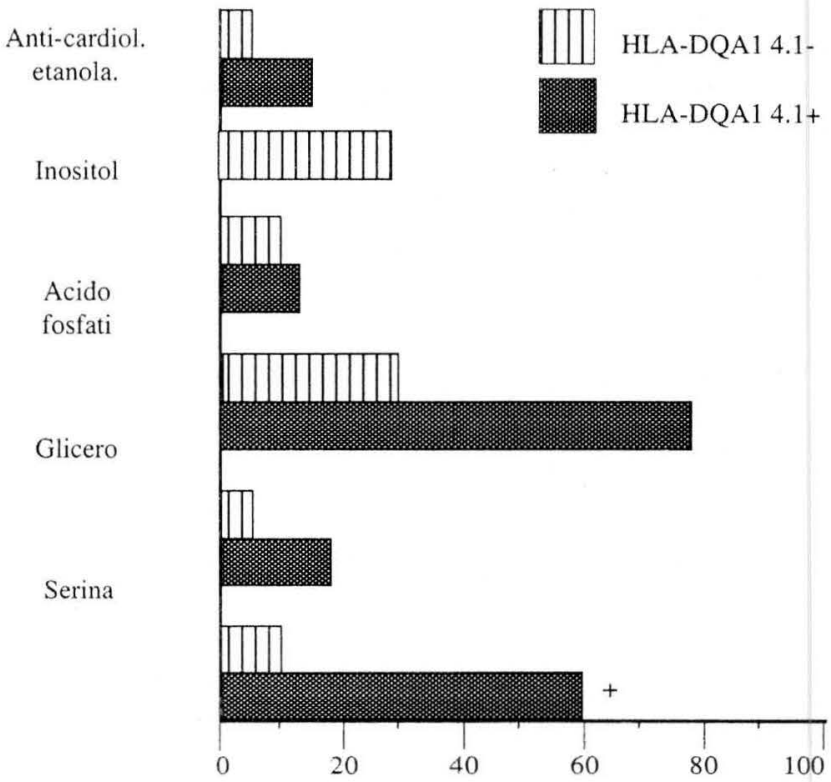

\section{Discusión}

Los porcentajes de nacimientos después de terapia con linfocitos para ARE varían ampliamente (13-14). Los datos presentados en este trabajo podrían ser una explicación a la variación de resultados. Mujeres que experimentan una nueva pérdida del embarazo después de terapia con linfocitos muestran unos incrementos importantes en los títulos de AAP comparadas con las mujeres que tuvieron un embarazo a término. Se ha descrito lo mismo en mujeres embarazadas con enfermedades autoinmunes quienes experimentan remisión o exacerbación de la enfermedad durante la gestación.

Se destaca que los tratamientos autoinmunes no benefician a todas las pacientes embarazadas. En fecha reciente se reportó la relación entre el HLA DQ ALFA 4.1 con las manifestaciones del síndrome AAP. Las mujeres que tienen HLA DQ ALFA 4.1 por análisis de genética molecular y cuyo feto presentaba este antígeno estaba a riesgo de desarrollar autoanticuerpos a las moléculas de fosfolípidos y perder su embarazo a pesar de un tratamiento adecuado. Estos hallazgos paralelos a los de Nelson quien demostró que las mujeres con artritis reumatoidea presentaban exacerbación durante el embarazo si el hijo era compatible con la madre en HLA DR y DQ. Las madres con artritis reumatoidea, cuyos fetos eran incompatibles con HLA DQ y embarazo. Experimentaban una remisión de los síntomas durante el embarazo. Es posible que una clase de genotipo materno fetal relacionado con los antígenos DQ ALFA y BETA son inaceptables desde el punto de vista de Autoinmunidad a sus madres y el embarazo se pierde por este mecanismo aún antes de que el proceso Aloinmune se estimule.

Es claro ahora que la inmunización con linfocitos paternos de mujeres que también tienen anormalidades autoinmunes está asociada con una rata de fracaso en el 
siguiente embarazo del $89 \%$, si no se inicia preconcepcionalmente y se continúa el tratamiento para el trastorno autoinmune. Los objetivos de la respuesta autoinmune en la madre parecen ser los Antígenos fosfolipídicos. La fisiopatología que determina una falla placentaria, no es simplemente un cambio en los mecanismos de coagulación dependientes de fosfolípidos o perturbación de la hemostasis natural fibrinolítica en todas las mujeres con antifosfolípidos y pérdida recurrente del embarazo. Hay una evidencia indirecta que los antifosfolípidos inhiben la fosfolipasa A1 y la Fosfolipasa C. Estas fosfolipasas estimulan la producción de hormonas glicoproteicas por las células placentarias. La Fosfatidilserina y la Fosfatilidetanolamina son moléculas de adhesión permitiendo la formación del sincitiotrofoblasto a partir del citotrofoblasto. La respuesta autoinmune en la madre puede alterar esta propiedad adhesiva de las moléculas de fosfolípidos con una retardada formación del sincitiotrofoblasto y pérdida recurrente del embarazo.

\section{BIBLIOGRAFIA}

1. Cowchock FS., Smith JB. and Glocial B. Antibodies to phospholipids and nuclear antigens in patients with repeated abortions. Am. J. Obstet. Gynecol. 1986; 155: 1002-1010.

2. Unander AM., Norberg R., Hahn L. and Arfors L. Anticardiolipin antibodies and complement in ninety nine women with habitual abortion. Am. J. Obstet. Gynecol. 1987; 156: 114-119.

3. Barbui T., Radici., Cortelazzo S., Rossi E., Calli M., Finazzi G. and Parzzini F. Antiphospholipid antibodies in early repeated abortions: a case controlled study. Fertil. Steril. 1988; 50: 589-592.

4. Kwak J., Gilman-Sachs A., Beaman K. and Beer AE. Autoantibodies in women with primary recurrent spontaneous abortion of unknown etiology. J. Reprod. Inmunol. 1992; 22: 15-31.

5. De Wolf F., Carreras LO., Moerman R., Van Assche A. and Renaer M. (1982). Decidual vasculopathy and extensive placental infarction in a patient with repeated thromboembolic accidents, recurrent fetal loss and lupus anticoagulant. Am. J. Obstet. Gynecol. 1982; 142: 829834.

6. Ferro D., Saliola M., Quintarelli C., Basili S., Grandilli A. and Bonavita MS. Methods for detecting lupus anticoagulants and their relation to thrombosis and miscarriage in patients with systemic lupus erythematosus. J. Clin. Pathol. 1992; 45: 332-338.

7. Session A. and Horowitz A. Differentiation related differences in the plasma membrane phospholipid asymmetry of mytogenic and fibrogenic cells. Biochem Biophys Acta. 1983; 728: 103-111.

8. Hasegawa I., Takakuwa S. and Kanazawa K. Cytotoxic antibody against trophoblast and lymphocytes present in pregnancy with intrauterine growth retardation and its relation to anti-phospholipid antibody. J. Reprod. Immunol. 1990; 17: 127-139.

9. Kwak J., Gilmn-Sachs A., Beaman K. and Beer AE. Reproductive outcome in women with recurrent spontaneous abortions of alloimmune and autoimmune etiologies; pre vs post conception treatment. Am. J. Obstet. Gynecol. 1992; 166: 1975-1987.

10. Molkentin J., Baxter-Lowe LA. Detection of 14 HLA DQB 1 alleles by oligotyping. Human. Immunol. 31: 114-122.

11. Kwak J., Barini R., Gilman-Sachs A., Beaman K. and Beer AE. Down regulation of maternal autoimmune response may determine pregnancy outcome. Am. J. Reprod. Immunol. 1992; 27: 24.
12. Kwak J., Barini R., Gilman-Sachs A., Beaman K. and Beer AE. Down regulation of maternal antiphospholipid antibodies during early pregnancy and pregnancy outcome. Society of Ginecologic Investigation 40th Annual meeting 1993; 107.

13. Beer AE., Zhu X., Semprini AE. and Quebbeman JF. Pregnancy outcome in human couples with idiopathic recurrent abortions: the role of female serum mixed lymphocyte culture blocking factors, potentiating factors and local uterine immunity before and after paternal leukocyte immunization. In Beer AE., Zhu X., Semprini AE. and Quebbeman JF. (eds). Immunological Approaches to Contraception and Promotion of Fertility, pp. Pages. Plenum Publishing. 1986.

14. Smith J. and Cowchock F. Immunological studies in recurrent spontaneus abortion: effects of immunization of women with paternal mononuclear cells on lymphocytotoxic amn mixed lymphocyte reaction blocking antibodies and correlation with sharing of HLA and pregnancy outcome. J. Reprod. Immunol. 1988; 14: 99.

15. Zurier, R.B. Sytemic lupus erythematosus and pregnancy. Clin. Rheum. Dis. 1975; 1: 613.

16. Kwak J., Ober C., Barini R. and Beer AE. Maternal autoimmune abnormalities and fetal HLA-DQA1 alleles in women with recurrent spontaneous abortion. Society for Gynecologic Investigation. San Antonio. 1992; 363.

17. Nelson J., Hughes KA., Smith A., Nisperos BB., Branchaud AM. and Hansen JA. Maternal-fetal disparity in HLA class II alloantigens and the pregnancy induced amelioration and rheumatoid arthritis. N. England. J. Med. 1993; 329: 446-471.

18. Gleicher N., Harlow L. and Zilberstein M. Regulatory effect of antiphospholipid antibodies on signal transduction: A possible model for autoantibody induced reproductive failure. Am. J. Obstet. Gynecol. 1992; 167: 637-642.

19. Handwerger S., Barret J., Markoff BF., Zeitler P., Cwikel B. and Siegel M. Stimulation of human placental lactogen release by araquidonic ascid. Mol. Pharmacol. 1981; 20:609-613. 